\title{
Geliştirilen Farklılaştırma Yaklaşımının Sanat Alanında Üstün Zekâlı ve Özel Yetenekli Öğrencilerin Yaratıcılıkları Üzerindeki Etkisi ${ }^{1}$
}

DOI: $10.26466 /$ opus. 906214

\author{
* \\ Filiz Kansu Celik* - Osman Çaydere ** \\ * Öğretmen, MEB, İstanbul/Türkiye \\ E-Posta: kanfiliz@gmail.com \\ ORCID: 0000-0002-8999-3947 \\ ** Doç.Dr, Gazi Üniversitesi/Gazi Eğitim Fakültesi, Ankara/Türkiye \\ E-Posta: osmancaydere@gazi.edu.tr \\ ORCID: 0000-0003-4004-1643
}

\begin{abstract}
Öz
Bu çalışmanın amacl, üstün zekâlı ve özel yetenekli öğrencilerin görsel sanatlar eğitimi için geliştirilen farklılaştırma yaklaşımının, öğrencilerin yaratıcılıkları üzerindeki etkisini belirlemektir. Geliştirilen farklılaştırma yaklaşımının, öğrencilerin sözel yaratıcılık ve şekilsel yaratıcılık puanlarının üzerinde etkisinin olup olmadı̆̆ı araştırılmıştır. Çalışma 2019-2020 ĕğitim öğretim yılı içerisinde, Aralık2019 ile Ocak-2020 ayları arasında, İstanbul' da bulunan bir Bilim ve Sanat merkezi, Özel Yetenekleri Geliştirme Programı 2'ye devam eden, 5 farklı grupta bulunan toplam sayıları 45 olan öğrenci grubu ile yürütülmüştür. Söz konusu araştırma, 'nicel araştırma deseni' kapsamında tek gruplu ön test-son test yöntemi ile yürütülmüş̧ür. Geliştirilen farklılaştırma yaklaşımının ne kadar etkili olduğunu ölçme amacıyla Torrance Yaratıcı Düşünce Testi kullanılmıştır. Torrance Yaratıcı Düşünce Testi'nden elde edilen verilerin çz̈zümlenmesi için, ilgili alanda eğitim almış bir uzmandan yardım alınmış ve söz konusu testin sonuçları tablolaştırılarak yorumlanmıştır. Araştırma sonuçlarına göre, sanat eğitimi alanında geliştirilen farklılaştırma yaklaşımının, üstün zekâlı ve özel yetenekli bireylerin sözel ve şekilsel yaratıcılı puanlarında anlamlı düzeyde farklılığa yol açtığı belirlenmiştir.
\end{abstract}

Anahtar Kelimeler: Üstün zekâ, özel yetenek, görsel sanatlar eğitimi, yaratıcılık, farklılaştırma yaklaşımı.

\footnotetext{
${ }^{1}$ Bu araştırma, Doç. Dr. Osman ÇayderedanışmanlığındaFiliz Kansu Çelik tarafında yapılan doktora tezinden üretilmiştir.
} 


\title{
The Effect of the Differentiation Approach Developed on the Creativity of Gifted and Talented Students in the Area of Art
}

\begin{abstract}
The aim of this study is to determine the effect of developed differentiation approach for visual arts education of gifted and talented students on students' creativity. It was researched whether the developed differentiation approach had an effect on the verbal creativity and modal creativity scores of the students.The research has been carried out in the 2019-2020 academic year, between December,2019 and January,2020, in a Science and Art Center in Istanbul, with a student group of 45 in 5 different groups, who are attending Special Abilities Development Program 2. The research as mentioned was conducted with a single group pre-test-post-test method within the scope of "quantitative research design". Torrance Creative Thinking Test was used to measure how effective the differentiation approach was. In order to analyze the data obtained from the Torrance Creative Thinking Test, assistance was received from an expert trained in the art area and the results of the test mentioned were tabulated and interpreted. According to the results of the research, it was determined that the differentiation approach developed in the area of art education caused a significant difference in verbal and modal creativity scores of gifted and talented individuals.
\end{abstract}

Keywords: Giftedness, special talent, visual arts education, creativity, differentiation approach. 


\section{Giriş}

Bir ülkenin gelişmesi, bireylerinin zekâ ve yetenek farklılıklarının en iyi şekilde değerlendirilerek nitelikli eğitim olanaklarına tam olarak ulaşabilmelerine bağlıdır. Devletlerin gelişebilmesi bağlamında üstün zekâlı ve özel yetenekli bireylerin rolü oldukça önemlidir. Üstün zekâlı ve özel yetenekli bireyler; eğitim ihtiyaçlarının karşılanması durumunda ülke gelişiminde önemli roller üstlenebileceklerdir. Üstün zekâlı ve özel yetenekli bireylerin eğitimlerinde kullanılan farklılaştırmalar, eğitimde gereken ihtiyaçların karşılanarak söz konusu bireylerin eğitim hedeflerine ulaşmalarında çok büyük rol oynadığı görülmektedir.

Üstün zekâlı ve özel yetenekli bireyler, uzman kişiler tarafından tanı almış ve herhangi bir alanda olağan üstü potansiyele sahip kişiler olarak tanımlanmaktadırlar. Söz konusu bireyler normal okullarında aldıkları eğitimden başka, farklılaştırılmış bir eğitime ihtiyaç duyarlar ve ancak bu şekilde kendilerine ve çevrelerine faydalı olurlar (Marland, 1972). Renzulli (1977)'ye göre yaşıtlarına oranla gelişimde ileride olmak, sorunların çözümünde rraksak düşünebilme yeteneğine sahip olmak ve yüksek görev bilincine sahip olmak üstün zekâlı olmanın en kapsayıcı özelliklerindendir(Renzulli'den aktaran Ataman, 2004).

Üstün zekâ ve özel yetenekle ilgili yapılan çalışmalar 19. yy başlarından itibaren temel olarak 2 ayrı kola ayrılır: müzik, spor, resim, dans alanlarındaki çalışmalar ve genel toplum eğitimi içinde farklılaştırma gerektiren bilişsel, duyuşsal ve yaratıcllğa ilişkin çalışmalar. (Akarsu, 2004).

Literatüre göre sanat alanında yetenekli bireyler için 3 ana kavram kullanılmaktadır. Bunlar plastik sanatlar alanında, müzik alanında ve drama alanında üstün yeteneklilik kavramlarıdır. Plastik sanatlar alanında üstün ve özel yetenekliler, çok erken yaşlarda ortalama üstü çizim becerisi ve üstün görsel hafızaya sahip olmanın yanında, sanatsal becerilerini ilerletme yönünde de yüksek motivasyon içerisindedirler (Levent ve Çelik, 2017). Sanat alanında yeteneğin ortaya çıması ve gelişmesi konusunda, estetik algının gelişimi çok önemli rol sahibidir. Estetik algı ise, bireyin doğumundan itibaren ortaya çlkmakta ve çevresel faktörlerle gelişme göstermektedir. Yaratıcılık gelişimi de, estetik algı gibi çevresel faktörlere bağlıdır (Tuna, 2017). Çevresel faktörler içerisinde 'eğitim' çok önemli bir rol sahibidir. 
Özel yetenekli ve üstün zekâlı bir çocuğun, normal zekâ potansiyeline bağlı bir çocukla aynı seviyede eğitime dâhil edilmesi, sıradan uygulamalarla başbaşa bırakılması, zaman içerisinde bireyin çalışma alışkanlıklarının kötüleşmesine sebep olabilmektedir (Cutts ve Mosaley, 2004). Bu gibi durumların önlenmesi için öğrencinin eğitim programında bazı farklılaştırmalara gidilmesi gerekmektedir. Tomlinson'a göre farklılaştırma 'uygun görevler, esnek gruplama, devam eden değerlendirme ve uyarlama gibi farklılaştırmaların genel prensipleri tarafından rehberlik edilen bir öğrencinin ihtiyaçlarına bir öğretmenin verdiği tepki'dir. Robinson ve Kolloff çeşitli branşlarda farklılaştırmaların, fen, dil sanatları, matematik, sanat ve diğer derslerde üstün yeteneğe sahip öğrencilerin eğitim ihtiyaçlarını karşılamada çok önemli bir yere sahip olduğunu belirtmişlerdir (Tomlinson, Robinson ve Kollof'tan aktaran Robinson, Shore ve Enersen, 2014).

Ülkemizde özel yetenekli ve üstün zekalı bireylerin eğitimleri için doğrudan adres gösterilebilecek tek kurum Milli Eğitim Bakanlığı bünyesindeki Bilim ve Sanat Merkezleri' dir (Bilsem). Bilsemler, özel eğitim daire başkanlığının düzenlemiş olduğu yönerge ile yönetilmektedirler. Söz konusu yönergede, üstün zekalı ve yetenekli çocukların seçimleri, tespitleri, eğitimleri ve öğretmenlerinin belirlenmesi ile eğitim alacakları kurumların işleyişlerine ilişkin usul ve esaslar belirtilmiştir (Milli Eğitim Bakanlığı, 2013). Bilsemler bünyelerinde uyum, destek eğitimi, özel yetenekleri geliştirilmesi, bireysel yetenekleri fark ettirme ve proje üretimi yönetimi eğitim programlarını barındırırlar (Milli Eğitim Bakanlığı, 2016). Bilsemlere seçilen öğrenciler uyum dönemini atlattıktan sonra, asıl seçilmiş oldukları programlara yönlendirilirler, bu programlardan biri de sanat alanında yetenekli bireylerin dahil edilmiş olduğu Özel Yetenekleri Geliştirme Programıdır. Özel yetenekleri geliştirici program, görsel sanatlar ve müzik alanında sanatsal ve bilimsel temelli, öğrenciyi merkeze alan, yaparak yaşayarak öğrenen ve bu doğrultuda çalışmalar üreten bireyler yetiştirmeyi hedefler (Milli Eğitim Bakanlığı, 2013).

Tasarlanan farklılaştıma yaklaşımının temelinin dayandırıldığı Carol Schlichter'ın Yetenekler Sınırsız Modeli, sınıflardaki çoklu yetenek yaklaşımını başarılı şekilde yönetebilmek için, öğretmenlerin gerekli beceri tutum ve bilgileri edinmelerine ve geliştirmelerine yardım eden bir gelişim programı tasarlayıp uygulamalarını sağlamaktır. Söz konusu modelde, öğrencilerin çoklu yetenek alanlarında gelişimlerine önem verilmektedir. Bu yakla- 
şımda öğrencilerin, üretken düşünme, tahmin etme, iletişim, planlama, karar verme ve akademik olmak üzere 6 farklı alanda sahip oldukları çoklu yetenekleri tanımalarına ve bu yeteneklerini geliştirmelerine yardımcı olmak amaçlanmıştır(Schlichter, 1986).

Literatür incelendiğinde farklılaştırma yaklaşımlarının üstün zekâlı ve özel yetenekli öğrencilerin yaratıclıkları üzerindeki etkilerinin (Kök, 2012), (Sayı, 2013), (Atalay, 2014), (Özyaprak, 2012), (Korkut, 2017), (Güney, 2018), (Ülger, 2019), (Umar, 2014), (Karip ve Kuru, 2018), (Altıntaş, 2014)araştırmalarında da artış yönünde olduğu belirlenmiştir.

$\mathrm{Bu}$ araştırmanın amacl; görsel sanatlar eğitimi için geliştirilen farklılaştırma yaklaşımının, Bilim ve Sanat Merkezinde eğitim almakta olan üstün zekâlı ve özel yetenekli öğrencilerin yaratıcılıkları üzerindeki etkisini incelemektir. Araştırma, öğrencilerin farklı ve yaratıcı düşünme becerilerini geliştirerek, üstün yetenekli/zekalı öğrencilerin yaratıclıkları üzerindeki etkisinin belirlenmesi açısından önemlidir. Ayrıca araştırma, geliştirilmiş farklılaştırma yaklaşımının dünyada uygulanan bir eğitim modeli çerçevesinde işlenen dersler karşısındaki durumunun araştırılarak etkililiğinin ortaya koyulmuş olması açısından da önemlidir.

Bu çerçevede söz konusu araştırmanın problem cümlesi: Görsel sanatlar eğitimi için geliştirilen farklılaştırma yaklaşımının, Bilim ve Sanat Merkezinde eğitim almakta olan üstün zekâlı ve özel yetenekli öğrencilerin yaratıcllıkları üzerinde bir etkisi varmıdır? Bu problemden hareketle aşağıdaki sorulara cevap aranmıştır:

1. Deney grubundaki üstün zekalı ve özel yetenekli öğrencilerin uygulama öncesi ve sonrasında sözel yaratıcılık puanları arasında bir fark var midır?

2. Deney grubundaki üstün zekalı öğrencilerin uygulama öncesi ve sonrasında şekilsel yaratıcılık puanları arasında anlamlı bir farklılık var midir?

\section{Yöntem}

Araştırmanın Modeli: Literatür incelendiğinde farklı sınıflara ait araştırma modelleri görülmektedir. Bilimsel çalışmalar ait oldukları felsefelere göre nitel, nicel ve karma desen olarak ayrılmaktadırlar. Var olan gerçekliği nesnel bir şekilde ortaya koyan pozitivist araştırma desenlerine nicel araştırma 
desenleri denir (Büyüköztürk, Çakmak, Akgün, Karadeniz ve Demirel, 2018). Bu araştırmada görsel sanatlar eğitimi için geliştirilen farklılaştırma yaklaşımının, Bilim ve Sanat Merkezinde eğitim almakta olan üstün zekâlı ve özel yetenekli öğrencilerin yaratıcılıkları üzerindeki etkisi incelenmeye çalışılmıştır. Farklılaştırma yaklaşımının uygulandığı grup, tek grup olarak seçilmiş ve ön test-son test Torrance Yaratıcılık Testi uygulaması yapılmıştır. Bu sebepten, çalışmanın deseni nicel araştırma yöntemlerinden tek gruplu araştırma yöntemi olarak belirlenmiştir. Bu araştırmada kullanılan tek gruplu araştırma yöntemi, uygulama yapılacak gruptaki birey sayısının çok az ve benzer özellikler göstermelerinden dolayı belirlenmiştir (Tharenou, Donohue ve Cooper, 2007). Söz konusu çalışma kapsamında nicel araştırma modellerine uygun olarak deneme öncesi modellerden ön test-son test modeli uygulanmıştır. Bu model dâhilinde seçilmiş gruba ilk olarak ön test uygulamasından sonra bağımsız bir değişken uygulanır, sonar da son test uygulaması yapılır ve her iki testin sonuçları karşılaştırılarak bağımsız değişkenin etkililiği ölçülür (Karasar, 2009).

Örneklem: Bu çalışmanın evrenini üstün zekâlı ve özel yetenekli öğrenciler, örneklemini de, İstanbul'da bulunan bir Bilim ve Sanat Merkezi'ndeki, 5 ayrı grupta bulunan, toplamda 45 kişilik Özel Yetenekleri Geliştirme Programı-2'ye dâhil öğrenci grubu oluşturmaktadır. Çalışma grubunda 30 kız, 15 erkek öğrenci bulunmakta olup Tablo 1'de gösterilmiştir.

Tablo 1.Çalışma grubu

\begin{tabular}{lll|l}
\hline Cinsiyet & Devlet Okulu & Özel Okul & Toplam \\
\hline Kız & 9 & 21 & 30 \\
Erkek & 4 & 11 & 15 \\
\hline
\end{tabular}

Söz konusu çalışmada, araştırmacının farklılaştırma yaklaşımını uyguladığı kurumda öğretmen olarak bulunması ve çalışmış olduğu alanın özel yetenekli ve üstün zekâlı bireyler arasında görsel sanatlar alanında tanınmış bireyler olması gerektiği için amaçlı örneklem kullanılmıştır. Kimi araştırmalarda evrenden, özel şartlar ve özellikler taşıyan bir örneklem kümesi alınması gerekmektedir, buna benzer durumlarda araştırmacılar, kendi bilgi ve tecrübelerinden hareketle çalışmaları için en uygun örneklemi seçerler. Seçilen örneklem kümesi amaca en iyi hizmet edebilecek şekilde seçilmiş olur (Özgen ve Gül, 2007). 


\section{Veri Toplama Araçları}

Söz konusu araştırmanın verileri ‘Torrance Yaratıcı Düşünce Testi' ile toplanmıştır.

Torrance Yaratıcı Düşünme Testi: Araştırmada kullanılan test, ilk olarak 1966 yılında ABD'de Ellis Paul Torrance tarafından yayınlanmıştır. Yaratıcılık seviyesini belirleyen bu test yaratıcıllğın, şekilsel ve sözel boyutlarını ölçen 10 alt testten oluşur. Söz konusu test A ve B formları olarak iki bölümden oluşmaktadır ve ilk test-son test olarak kullanılabilmektedir. Sözel bölümde, her aktivite bir uyaran resimle başlar ve test katılımcısı resme yazılı olarak yanıt verir. Puanlama bileşenleri ise akıcılık, özgünlük ve esneklik alt bileşenlerini içerir. Şekilsel bölümde ise; resim kurgulama ile ilgili 3 etkinlik bulunmaktadır. Şekilsel bölümün puanlama bileşenleri ise: akıcllık, özgünlük, detaylandırma, başlıkların soyutluluğu, erken kapanmaya direnç, hissel dışa vurma, olayları ifade etme, hareket, espri, hayal kurmadaki zenginlik, çizgilerin ya da çemberlerin sentezi, tamamlanmamış şekillerin sentezi, sıra dışı görselleştirme, içsel olarak görselleştirme, sınırları geçme, renkli hayal gücü, fantezi kurma ve başlıkların ifade edilmesindeki güçtür (Kim, 2017).

Testin orijinalinin güvenirlik çalışmalarında, A ve B formlarındaki testlerin hepsi, 4., 5., ve 6. Sinıflarda okuyan 118 bireye uygulanmış ve devamlılık katsayıları bulunmuştur. Uygulamalardaki en düşük korelasyon sayısı (.50) şekilsel yaratıcılık, en yüksek kat sayı ise (.93) sözel akıcılı̆ga aittir (Torrance'dan aktaran Aslan, 2001). Test, Türkçe diline adaptasyon çalışmalarında dilsel olarak eşdeğerlik, geçerlik ve güvenirlik çalışmaları yapılarak bütün yaş gruplarına uygun hale getirilmiştir. Anaokulu seviyesinden, üniversite seviyesine kadar bireylerden ve farklı meslek gruplarından, toplamda 922 kişiden veri toplanmıştır. Testin Türkçe ve tekrar İngilizce' ye çevrilmesinden sonra güvenirlik-geçerlik çalışmaları yapılmıştır(Aslan, 2001). Söz konusu çalışmalar aşağıdaki Tablo 2'de özetlenmiştir:

$\mathrm{Bu}$ araştırmada ilk hafta, öğrencilere yaratıcı düşünce testinin A formları, eğitimden sonraki hafta da B testleri uygulanmıştır. Sözel bölüm için etkinlik başına 5 dakika, şekilsel bölüm için de 10 'ar dakika süre verilmiştir. Sözel bölüm için toplamda 45 dakika, şekilsel bölüm için ise toplamda 30 dakika sure ayrilmıştır. 
Tablo 2.Torrance yaratıcılık testi ilköğretim kademesi için iç tutarlılık sonuçlarn

\begin{tabular}{lllll}
\hline Öğr. Say. (N=144) & Söz. AK. & Söz. Esn. & Söz. Orij. & Şek. Top. \\
\hline Cronbach Alfa & 0,86 & 0,74 & 0,73 & 0,64 \\
Spearman & 0,89 & 0,68 & 0,57 & 0,74 \\
Brown & 0,89 & 0,62 & 0,56 & 0,51 \\
Guttman & & & & \\
\hline
\end{tabular}

Eğitim Materyali (Üstün Zekâlı ve Özel Yetenekli Öğrencilerin Sanat Ĕ̆itimine Yönelik Bir Farkhlaştırma Yaklaşımı: Bu çalışma Aralık 2019 ile Ocak 2020 tarihleri arasında gerçekleştirilmiştir. Bu araştırmada, geliştirilen farklılaştırma yaklaşımı için, Bilsem Etkinlik Kitabı'ndan "Göç" konusu ele alınmıştır. Göç konusu için geliştirilen modül üzerinden birtakım zenginleştirmeler ve farklılaştırmalar yapılmıştır. Farklılaştırmalar yapılırken Carol Schlichter'in yetenekler sinırsız modelinden faydalanılmış ve hedef davranışlar ile eğitim sisteminin temel hatlarını oluşturan hedef, içerik, süreç ve değerlendirme alanlarınada düzenlemeler yapılmıştır. Bu alanlar: "Hedefler: Geliştirilmiş ve yenilenmiş kazanımlar, İçerik: konu, Süreç: öğrenme ortamları, öğretme yöntem ve teknikleri, eğitim materyalleri, Değerlendirme: Sergileme ve eser eleştrisi" olarak tanımlanmışlardır. Farklılaştıılıış yaklaşımın 'Hedefler' kısmında, Carol Schlichter'in “Yetenekler Sınırsız" modelinden faydalanılarak geliştirilmiş, yeniden yazılmış ve zenginleştirilmiş kazanımlara yer verilmiştir. Araştırmanın "İçerik" kısmında ise, yetenekler sınırsız modelindeki kazanımlara uyarlanabilirlik açısından uygun olan, görsel sanatlar etkinlik kitabından "Göç" konusu seçilip kullanılmıştır. $\mathrm{Bu}$ aşamada öğrencilere uyandırıcı sorular, belgesel izlemeleri, çeşitli gazate, dergi, broşür, literature taramaları ve eser incelemeleri ile konuya üst düzey ve özgün bakış açısı geliştirmeleri hedeflenmiştir. Araştırmanın "Süreç" kısmında ise, öğrenme ortamları, öğretme yöntem ve teknikleri, eğitim materyallerine yer verilmiştir. Öğrenme ortamları olarak mevcut Bilim ve Sanat merkezindeki sanat atölyeleri kullanılmıştır. Atölyelerdeki akıllı tahtalar ve bilgisayarlar aracılığıyla, araştırmanın içerik kısmı ile ilgili belgesel gösterimi, sanatçı ve eser incelemeleri, sanal geziler düzenlenmiştir. Sanat eğitimi ana öğrenme alanlarından görsel iletişim ve biçimlendirme, kültürel miras, sanat eleştirisi ve estetik alanlarında (Milli Eğitim Bakanlığ1, 2018) beceri kazanımı sağlanması için göstererek yaptırma, yaparak ve yaşayarak öğrenme, proje tabanlı öğrenme yöntemlerine yer verilmiştir. Farklılaştırma 
yaklaşımının“Değerlendirme”"kısmında ise farklılaştırma yaklaşımı uygulandıktan sonra ortaya çıkan eserlerin sergilenmesi dâhilinde öğretmen rehberliğinde ve öğrenciler arasında yapılan eser eleştirisi ve uygulama dışında en son adım olarak da Torrance Yaratıcılık testi uygulaması yapılmıştır.

Farklılaştırma yaklaşımının uygulanması toplamda 4 hafta sürmüş, öncesinde yaratıclık testinin A formları öğrencilere uygulanmıştır. İlk hafta hazırlık haftası olarak belirlenmiş, 2. ve 3. haftalar uygulama, 4 . ve son hafta da değerlendirme (sergileme) haftası olarak belirlenmiştir. Her ders saati $40+40=80$ dakika olacak şekilde oluşturulmuştur. Toplamda 5 ÖYG sınıfı ile çalışılan farklılaştırma yaklaşımı programında, ilk hafta hazırlık haftası olarak kararlaştırılmıştır. Bu haftada bilgi seviyesinin belirlenebilmesi için konu ile ilgili sınıfta açık tartışma yapılmış, yetenekler sınırsız modeline göre 6 farklı alandaki kazanımlar belirlenmiş, kazanımlara ulaşılabilecek şekilde öğretme, öğrenme stratejileri belirlenmiştir. Öğrencilere konu ile ilgili hem sanat tarihi dâhilinde hem de günümüz sanatı dâhilinde bilgi toplamaları için danışmanlık sağlanmış, edindikleri bilgileri sınıf içerisinde tartışma yolu ile değerlendirilmiştir. Bu aşamada kavram geliştirme çalışmaları yaptırılmış, sanat eserinin kavramsal alt yapısı oluşturulmaya çalışılmıştır. Öğrencilerin mevcut konu hakkında sanatsal duyarlılık geliştirmeleri sağlanmıştır.

Uygulama sürecinde ise 2 . ve 3 . haftalar $2+2$ ders saati olarak planlanmıştır. Bu haftalar dâhilinde, hazırlık sürecinde kavram geliştirme çalışmasında elde edilen temaların üzerine gidilmiş ve kavramlardan yola çıkılarak özgün içerikli sanatsal çalışmalar oluşturulmaya çalışılmıştır. Çalışma öncesinde ve esnasında kullanılacak teknikler ile ilgili öğrencilere rehberlik edilmiş, öğrencilerin özgür bir şekilde istedikleri tekniği seçmeleri sağlanmiştır.

Değerlendirme (sergileme) süreci ise 4 . hafta da gerçekleştirilmiş, öğrencilerin Göç ve Göçmenler ile ile ilgili geliştirmiş oldukları kavramlar etrafında yapmış oldukları çalışmalar sergilenmiş ve eser eleştirisi yapılmıştır.

\section{Verilerin Analizi}

$\mathrm{Bu}$ araştırmaya dâhil edilen 45 öğrenci için nicel veriler SPSS21 programı kullanılarak çözümlenmiştir. Sözel yaratıcılık testinde 2 adet öğrencinin, test 
maddelerinin yarısından fazlasına cevap vermemelerinden dolayı uç değer göstermiş oldukları tespit edilince test veri setinden çıkartılmışlardır. Araştırma analizi 43 öğrenci üzerinden yürütülmüştür. Sözel yaratıcılık bölümü testinin standart puanlamasında toplam sözel yaratıcılık alt testlerin ortalaması 100, standart sapması 20 olan bir dağılıma dönüştürülerek elde edilmektedir. Fakat böyle bir standartlaştırma grup otalamaları arasındaki farkları görmeye engel olmaktadır. Ham puanların toplanabilir olduğu düşünülerek toplam sözel yaratıcılık için standart puan yerine ham puanların toplamı kullanılmıştır. Hem sözel hem de şekilsel yaratıcılık testlerinde ilk-son test uygulamaları arasındaki farkın $\alpha=0,05$ düzeyinde anlamlı bulunan sonuçları için bağımsız değişkenin (uygulama) bağımlı değişken (yaratıcılık puanları) üzerindeki etkisi eta-kare (n2) istatistiğiyle incelenmiştir. Parametrik test varsayımları sağlandığı için non-parametrik test yapılmamıştır.

\section{Bulgular}

Birinci Alt Probleme İlişkin Bulgular: Bu araştırma için elde edilen veriler SPSS 21 programı kullanılarak çözümlenmiştir. Sözel yaratıclık bölümüne ait alt test verileri incelendiğinde, iki öğrencinin test maddelerinin yarısından fazlasına cevap vermemelerinden dolayı, sonuçlarda uç değerler ortaya çıkması nedeniyle, test setinden çıkarılmışlardır. Bu sebepten, analizler 43 öğrenci üzerinden yürütülmüştür.

Birinci alt problem olarak 'öğrencilerin ilk ve son test sözel yaratıclık puanları arasında fark var mıdır?' sorusunun cevabı olarak aşağıdaki Tablo 3 incelendiği takdirde, ilişkili örneklemler $t$ testi sonuçlarından da anlaşılacağı üzere ilk test ve son test puanları arasında anlamlı farklılıklar görülmektedir.

Testin Akıcılık boyutundaki sonuçları $(\mathrm{t}=14,63 ; \mathrm{p}<0,05)$, Esneklik boyutundaki sonuçlanı $(t=-14,78 ; p<0,05)$, Orijinallik boyutundaki sonuçlanı ( $t=-$ 9,10; $p<0,05)$, Gözlemlenen sonuçların, söz konusu farklılaştırma yaklaşımının sözel yaratıclık puanlarına etmiş olduğu etkinin anlamlı derecede farklılaştığı toplam sözel yaratıcılık son test ortalama puanlarından da görülmektedir $(t=-15,30 ; p<0,05)$. 
Tablo 3.Sözel yaratıcılık puanlarını ön-son test uygulamalarına göre ilişkili örneklemler t testi sonuçlarn

\begin{tabular}{|c|c|c|c|c|c|c|c|c|}
\hline Alt test & Uygulama & $\mathbf{N}$ & $\overline{\mathbf{X}}$ & S.S. & $t$ & sd & $\mathrm{p}$ & $\eta^{2}$ \\
\hline \multirow{2}{*}{ Akıcılık } & Ön test & 43 & 15,16 & 4,39 & \multirow{2}{*}{$-14,63$} & \multirow{2}{*}{42,00} & \multirow{2}{*}{$0,00^{*}$} & \multirow{2}{*}{0,84} \\
\hline & Son test & 43 & 35,88 & 8,76 & & & & \\
\hline \multirow{2}{*}{ Esneklik } & Ön test & 43 & 10,33 & 2,68 & \multirow{2}{*}{$-14,78$} & \multirow{2}{*}{42,00} & \multirow{2}{*}{$0,00^{*}$} & \multirow{2}{*}{0,84} \\
\hline & Son test & 43 & 22,35 & 4,79 & & & & \\
\hline \multirow{2}{*}{ Orijinallik } & Ön test & 43 & 6,51 & 3,63 & \multirow{2}{*}{$-9,10$} & \multirow{2}{*}{42,00} & \multirow{2}{*}{$0,00^{*}$} & \multirow{2}{*}{0,66} \\
\hline & Son test & 43 & 15,21 & 5,71 & & & & \\
\hline \multirow{2}{*}{ Sözel Yaratıcılık } & Ön test & 43 & 32,00 & 9,16 & \multirow{2}{*}{$-15,30$} & \multirow{2}{*}{42} & \multirow{2}{*}{$0,00^{*}$} & \multirow{2}{*}{0,85} \\
\hline & Son test & 43 & 73,44 & 16,82 & & & & \\
\hline
\end{tabular}

İkinci Alt Probleme İlişkin Bulgular: Ikinci alt problem olan, öğrencilerin şekilsel yaratıcılık puanlarının ilk test ve son test arasındaki farklarının açıklaması, şekilsel yaratıclık indekslerine ilişkin bulguları, yaratıcılık indeksi ön-son test uygulamalarına göre ilişkili örneklemler $\mathrm{t}$ testi sonuçları tablosunda görüldüğü gibidir. Tablo 4 incelendiğinde yaratıcllı indeksinin ön test ortalaması 104,56 iken, son test ortalamsı 111,98 e yükselmiştir. Arada gözlenen fark istatistiksel olarak anlamlıdır ( $t=-2,84 ; \mathrm{p}<0,05)$. Geliştirilen farklılaştırma yaklaşımı öğrencilerin şekilsel yaratıcılık puanlarına \%15 oranında olumlu etki etmiştir $\left(\mathrm{n}^{2}=0,15\right)$. (Hakem değerlendirmesinde bahsedilen tablo yorumu burada yapılmıştır)

Tablo 4.Yaratıcılık indeksinin ön-son test uygulamalarnna göre ilişkili örneklemler t testi sonuçları

\begin{tabular}{lllllllll}
\hline Puan & Uygulama & $\mathbf{N}$ & $\overline{\mathbf{X}}$ & S.S. & $\mathbf{t}$ & sd & $\mathbf{p}$ & $\mathbf{\eta}^{2}$ \\
\hline \multirow{2}{*}{ Şekilsel yaratıcilık indeksi } & Ön test & 45 & 104,56 & 15,65 & \multirow{2}{*}{2,84} & \multirow{2}{*}{44} & \multirow{2}{*}{$0,01^{*}$} & \multirow{2}{*}{0,15} \\
& Son test & 45 & 111,98 & 14,61 & & & & \\
\hline
\end{tabular}

${ }^{*} p<0,05$

\section{Tartışma ve Sonuç}

Bu çalışmada, geliştirilen farklılaştırma yaklaşımının Torrance Yaratıcllık Testi sözel yaratıcılık alanı ile ilgili sonuçları, akıcılık, esneklik ve orijinallik alanlarında ölçülmüss ve bu alanlarda anlamlı farklılıklar meydana geldiği görülmüştür. Toplam sözel yaratıcılık alanı puanının 0.85 olarak belirlenmiş olması, geliştirilen farklılaştırma yaklaşımının, bireylerin sözel yaratıcılıkları üzerindeki etkisini göstermektedir. Dolayısıyla, farklılaştırma yaklaşımının sözel yaratıclığa olumlu katkı yaptığı söylenebilir. Sözel yaratıclık alnında 
elde edilen verilerden hareketle, Genç'in (2017) araştırmasında konu edindiği nitelikli bir eser oluşturulabilmek için, sanatın içsel yönünün oluşturulabilmesi gerekir. Bu doğrultuda, zihinsel etkinlik, hayal gücü, imgesel ifade gücü ve bu etmenlere bağlı olarak gereken ortalama üstü zekâ kapasitesinin arttırılabileceği düşünülmektedir. Atalay (2014) ve Özyaprak'ın (2012) çalışmalarında da farklılaştırılmış müfredat yaklaşımları uygulanmış ve sonuçları Torrance Yaratıcılık Testi puanları ile elde edilmeye çalışılmıştır. Her iki çalışmada da öğrencilerin derse karşı tutumlarında, eleştirel düşünme ve yaratıcılık düzeylerinde olumlu anlamda artış olmuştur. Bu doğrultuda araştırmaların sonuçları, söz konusu bu çalışma ile paralellik göstermektedir.

Geliştirilen farklılaştırma yaklaşımının şekilsel öntest ve son test puanlarında görüldüğü gibi, yaratıcllık puanları olumlu yönde belirgin şekilde artış göstermiştir.

Şekilsel yaratıcılık ile sözel yaratıcılık puanları incelendiğinde, sözel yaratıclık puanlarındaki artışın daha fazla olduğu dikkati çekmektedir, bunun sebebinin, tasarlanan farklılaştırma yaklaşımının bireylerin bilişsel becerilerinin gelişimine daha fazla katkı sağladığı söylenebilir. Dolu ve Üstün'ün çalışmasında belirtildiği üzere, Bilsemlere kabul edilen öğrencilerin WISC-R testi ile kabul edilmelerinden dolayı, bireylerin karakteristik olarak sözel yaratıcılıklarının gelişmesine daha yatkın oldukları da söylenebilir. Çalışma grubunun 13'ünün devlet, 32' sinin özel okullara gittiği göz önünde bulundurulduğunda, sözel yaratıcllıklarının gelişmesinde okul türlerinin de etken olabileceği düşünülmektedir.

Genç'in (2017) çalışmasında sanat eserinin sadece biçimsel olarak değil, içeriksel olarak da sağlam bir felsefi alt yapıya sahip olması gerektiği belirtilmiştir. Sözel yaratıcılık puanlarından elde edilen verilere bakılacak olursa, tasarlanan farklılaştırma yaklaşımının bu ihtiyacı karşılayacağı düşünülmektedir. Aynı zamanda, Levent ve Çelik'in (2019) çalışmasında Bilsemlerin atölye ve techizat konusunda yaşamış oldukları sıkıntılardan dolayı çoğunlukla geleneksel sanatlara yönelmiş oldukları ve daha çok zanaat alanlarında çalışmalar yapmaya elverişli oldukları belirtilmiştir. Bilsemde sanat alanında tanı almış olan öğrencilerin imgesel ve soyut düşünme becerilerinin gerekli düzeylerde gelişebilmesi için ilgili alanlarda çalışmalar yapmaya ihtiyaç duymaktadırlar ve tasarlanan farklılaştırma yaklaşımının da bu ihtiyaçlara cevap verdiği düşünülmektedir. 
Üstün zekâlı ve özel yetenekli bireylerin eğitimlerinde farklılaştırma yaklaşımlarının, bireylerin yaratıcılıkları üzerindeki olumlu anlamdaki etkilerini, Kök (2012) ve Sayı (2013) çalışmalarında da görmekteyiz. Kök'ün çalışmasında farklılaştırılmış geometri eğitiminin üstün zekalı bireylerin yaratıcllık, uzamsal düşünme becerileri ve başarılarına etkilerini olumlu anlamda etkilediği görülmüştür. Sayı'nın çalışmasında da farklılaştırılmış yabancı dil öğretiminin öğrencilerin yaratıcı ve eleştirel düşünmeye etkisi incelenmiş ve üzerinde farklılaştırma yapılan ünite konusu işlenerek bireylerin bu eğitim sonucunda yaratıcılık, eleştirel düşünme ve başarıları anlamlı düzeyde artmıştır. Bu sebeplerden dolayı araştırmanın sonuçları yukarıdaki araştırmalarla da paralellik göstermektedir.

\section{Öneriler}

- Üstün zekâlı ve özel yetenekli bireylerin sanat alanında sözel yaratıcllık becerilerini kullanabilmeleri için uygun ortamlar oluşturulmalıdır. Öğrencilerin entelektüel becerilerinin gelişimleri sağlanmalıdir.

- Zekâ ve sanatsal duyarlılığın geliştirilebilmesi için günümüz dünya problemleri üzerinde düşünebilmek, toplumların sorunlarına karşı duyarlılık geliştirebilmek ve yaratıcı çözümler üretebilmek için özgün bir bakış açısına sahip olunması gerektiği düşünülmektedir. Bu doğrultuda öğrencilerin ders konuları ve eğitim uygulamaları, gerçek yaşamdaki sorunlara etkin çözümler üretebilecekleri bir işlevsellik de oluşturulabilir.

- Öğrencilerin sanatsal duyarlılıklarından faydalanarak, çalışmalarında etkin olarak zekâ potansiyellerini kullanmalarını sağlamak, üstün zekâlı ve özel yetenekli bireylerin sanatsal eğitimlerinde en önemli hedef olarak görülmelidir. Bu noktada zekâ potansiyellerini üst noktalara çkarabilecekleri uygun konu ve eğitim ortamlan ile buluşturulmalıdırlar.

- Üstün zekâlı ve özel yetenekli bireylerin sanatsal eğitim içerikleri oluşturulurken, üstün zekâlılar için özel olarak geliştirilmiş eğitim programları temel olarak alınabilir ve zaman, mekân, imkân vb. durumlar açısından farklılaştırılarak kullanılabilirler. 
- Üstün zekâlı ve özel yetenekli bireyler görsel sanatlar alanında tanı almış olsalar bile, başka branşlarda da yoğun programlara dâhil edildiklerinden, sanat eğitimi alanlarının yetersiz kalmaması için aileleri tarafından gerekli önlemler alınmall, maddi ve manevi olarak desteklenmelidirler.

- Görsel sanatlar alanında tanı almış olan bireylerin, tanılama süreçlerinden sonra sanatsal gelişimleri, diğer eğitimlerinin (destek eğitimi, bireysel yetenekleri fark ettirici program vb.) gölgesinde kalmayacak şekilde devlet tarafından da desteklenmeli, bireylerin karakteristik özelliklerinin sanatsal alanda da gelişebilmesi için kendilerine gerekli zaman, mekân, malzeme ve yetişmiş öğretmen ihtiyaçlarının karşılanması gerekmektedir. 


\title{
EXTENDED ABSTRACT \\ The Effect of the Differentiation Approach Developed on the Creativity of Gifted and Talented Students in the Area of Art
}

\author{
Filiz Kansu Çelik- Osman Çaydere \\ MONE- Gazi University
}

The aim of this study is to examine the effect of the developed differentiation approach for visual arts education on the creativity of gifted and talented students studying at the Science and Art Center. The research is important in terms of determining the effect on the creativity of gifted/intelligent students by developing different and creative thinking skills of students.In addition, the research is important in terms of revealing the effectiveness of the developed differentiation approach by researching the situation of the lessons taught within the framework of an education model applied in the world.

In this context, the problem statement of the aforementioned research is: "Does the developed differentiation approach for visual arts education have an effect on the creativity of gifted and talented students studying at the Science and Art Center?". Based on this purpose, the following questions were sought:

1. Is there a difference between the verbal creativity scores of the gifted and talented students in the experimental group before and after the application?

2. Is there a significant difference between the figural creativity scores of the gifted students in the experimental group before and after the application?

The group in which the differentiation approach was applied was selected as a single group and the pre-test-post-test Torrance Creativity Test was applied.For this reason, the pattern of the study was determined as a single-group research method from the quantitative research methods.The single-group research method used in this study was determined because the number of individuals in the group to be applied was few and showed similar characteristics.Within the scope of this 
study, pre-test-post-test model was applied from pretest models in accordance with quantitative research models.

The working area of this study consists of gifted and talented students, and the sample is a student group included in the Special Talent Development Program-2, consisting of 45 people in 5 different groups in a Science and Art Center in Istanbul.There were 30 female and 15 male students in the study group, the researcher was used differentiation approach in the study in question, having the researcher as a teacher in the institution where he/she applied the differentiation approach and purposive sampling was used as there should be well-known individuals in the area of visual arts among gifted individuals.

The data of the research in question were collected with the 'Torrance Creative Thinking Test'. The test used in the research was first published by Ellis Paul Torrance in the USA in 1966. This test, which determines the level of creativity, consists of 10 subtests that measure the formal and verbal dimensions of creativity. The test in question consists of two parts as A and B forms and can be used as the first test and post test. Required validity and reliability studies have been carried out in adapting the test to our country.In this study, the A forms of the creative thinking test were performed to the students in the first week, and the B tests were performed the following week. 5 minutes for the verbal part and $10 \mathrm{mi}-$ nutes for the formal part were given. A total of 45 minutes is allocated for the verbal part and 30 minutes for the formal part.

This study was carried out between December 2019 and January 2020. In this research, for the developed differentiation approach, the subject of "Migration" from the Bilsem Activity Book was discussed. Some enrichments and differentiation have been made through the developed module for migration. While making the differentiations, Carol Schlichter's unlimited talents model was used and arrangements have also been made to target behaviors and the areas of target, content, process and evaluation that form the basic lines of the education system.

Quantitative data for 45 students included in this study were analyzed using the SPSS21 program. When it was determined that 2 students showed extreme values in the verbal creativity test because they did not respond to more than half of the test items, they were removed from the test data set. Research analysis was carried out on 43 students. The ob- 
served results had a positive effect of $0.85 \%$ on the total verbal creativity post-test average score, in which the effect of the differentiation approach on verbal creativity scores differed significantly. The developed differentiation approach had a positive effect of $15 \%$ on the students' formal creativity scores.

In this study, the results of the developed differentiation approach in the Torrance Creativity Test related to verbal creativity were measured in the areas of fluency, flexibility and originality, and it was observed that there were significant differences in these areas.

When the formal creativity and verbal creativity scores are examined, it is noteworthy that the increase in verbal creativity scores is higher. It can be said that the reason for this is that the designed differentiation approach contributes more to the development of individuals' cognitive skills.In Bilsem, students who have been diagnosed in the area of art need to work in related areas in order to develop their imaginative and abstract thinking skills at the required levels and the designed differentiation approach is thought to respond to these needs.From this point on, the development of students' intellectual skills should be provided. A functionality can also be created where students can produce effective solutions to course subject, educational applications and real-life problems. They should be brought together with appropriate subjects and educational environments where they can maximize their intelligence potential. While creating artistic educational contents of gifted and talented individuals, specially developed training programs can be taken as a basis for gifted people and time, place, possibility etc. can be used by differentiating.Artistic development of individuals who have been diagnosed in the area of visual arts after the diagnosis process should be supported primarily by the state in a way that it will not be overshadowed by other educations (support training, individual talent awareness program etc.), and the needs of time, space, materials and trained teachers must be met in order for the characteristic features of individuals to develop in the artistic area as well. It is vital for the development of individuals that the families of gifted and talented individuals fulfill their responsibilities in meeting their educational needs. 


\section{Kaynakça / References}

Akarsu, F. (2004). Üstün yetenekli çocuklar seçilmiş makaleler kitabı. M. R. Şirin, A. Kulaksızoğlu ve A. E. Bilgili (Ed.), Üstün yetenekliler içinde s.127. İstanbul: Çocuk Vakfi.

Altıntaş, E. (2014). Üstün zekâlı öğrenciler için yeni bir farklılaştırma yaklaşımının geliştirilmesi ve matematik öğretiminde uygulanması. Doktora Tezi, Marmara Üniversitesi, Eğitim Bilimleri Enstitüsü, İstanbul.

Aslan, E. (2001). Torrance yaratıc düşünme testinin Türkçe versiyonu. M.Ü. Atatürk Ĕ̈itim Fakültesi Ĕ̆itim Bilimleri Dergisi, 14, 19-40.

Atalay, Ö. Z. (2014). Farklılaştırılmış sosyal bilgiler öğretiminin üstün zekâlı öğrencilerin akademik başarı, tutum, eleştirel düşünme ve yaratıcılıklarnna etkisi. Doktora Tezi. İstanbul Üniversitesi, Eğitim Bilimleri Enstitüsü, İstanbul.

Ataman, A. (2004). Üstün yetenekli çocuklar seçilmiş makaleler kitabı. M. R. Şirin, A. Kulaksızoğlu ve A. E. Bilgili (Ed.), Üstün zekâlı ve üstün özel yetenekli çocuklar içinde s.155. İstanbul: Çocuk Vakfi.

Büyüköztürk, Ş., Çakmak, E., Akgün, Ö. E., Karadeniz, Ş. ve Demirel, F. (2018). Bilimsel araştırma yöntemleri. Ankara: Pegem.

Cutts, N.E.veMoseley, N. (2004). Üstün zekâl ve yetenekli çocukların eŏitimi (İ. Ersevim, Çev.). İstanbul: Özgür.

Genç, M. A. (2017). Görsel sanatlarda yetenekli öğrenciler ile zihinsel yetenekli öğrencilerin resim becerilerinin karşılaştırmalı analizi. Abant İzzet Baysal Üniversitesi Ë̆itim Fakültesi Dergisi, 17(2), 679-692.

Genç, M. A. (2017). Üstün yetenekli öğrencilerin resim uygulamalarında zekâ. Ahi Evran Üniversitesi Kırşehir Eğitim Fakültesi Dergisi, 18(1), 643-655.

Güney, K. K. (2018). Üstün yetenekli öğrenciler için geliştirilen farklılaştırılmış bilimsel araştırma yöntemleri programınm değerlendirilmesi. Doktora Tezi, Karadeniz Teknik Üniversitesi, Eğitim Bilimleri Enstitüsü, Trabzon.

Karasar, N. (2009). Bilimsel Araştırma Yöntemi. Ankara: Nobel.

Karip, F. ve Kuru, A.Ç. (2018). Farklılaştırılmış görsel sanatlar öğretiminin 7. sınıf öğrencilerinin akademik başarılarına etkisi. İdil Dergisi, 7(42), 151-161.

Kim, K. H. (2017). TheTorrancetests of creativethinking-figuralorverbal: whichoneshouldweuse? Creativity. Theories-Research-Applications, 4(2), 304-305.

Korkut, Ş. (2017). Üstün yetenekli öğrencilerin eğitiminde bütünleştirilmiş müfredat modeline göre farklılaştırılmış sosyal bilgiler öğretimi. Yüksek Lisans Tezi. İnönü Üniversitesi, Eğitim Bilimleri Enstitüsü, Malatya. 
Kök, B. (2012). Üstün zekâl ve yetenekli öğrencilerde farkllaş̧tırlmış geometri öğretiminin yaratıchlı̆̆a, uzamsal yeteneğe ve başarrya etkisi. Doktora Tezi. İstanbul Üniversitesi Sosyal Bilimler Enstitüsü, İstanbul.

Levent, F. ve Çelik, F.K. (2017). Sanat alanında üstün yetenekli çocukların eğitiminin devlet tarafından desteklenmesine ilişkin sanatçların görüşleri. Türk Üstün Zekâ ve Ĕ̆itim Dergisi, 7(2), 67.

Levent, F. ve Çelik, F.K. (2019). Bilim ve sanat merkezlerinde görev yapan görsel sanatlar öğretmenlerinin özel yetenekli öğrencilerin sanat eğitimine ilişkin görüşleri. Opus Uluslararası Toplum Araştırmaları Dergisi,13(19), 750-785.

Marland, S.P. (1972). Education of thegiftedandtalented. Washington: U.S. Government Printing Office.

Milli Eğitim Bakanlığı (2013). Özel yetenekli bireyler strateji ve uygulama planı 20132017https://orgm.meb.gov.tr/meb iys dosyalar/2013 10/25043741 zelyeten eklibireylerstratejiveuygulamaplan20132017.pdfsayfasından erişilmiştir. Erişim tarihi. 20.10.2020

Milli Eğitim Bakanlı̆̆ (2016). Bilim ve sanat merkezleri yönergesi. orgm.meb.gov.tr/meb_iys_dosyalar/2016_10/07031350_bilsem_yonergesi.p df sayfasından erişilmiştir. Erişim tarihi. 22.01.2021

Milli Eğitim Bakanlığı (2018). Görsel sanatlar dersi öğretim programı http://mufredat.meb.gov.tr/Dosyalar/2018121111026326-

GORSEL\%20SANATLAR.pdfsayfasından erişilmiştir. Erişim tarihi. 15.11.2020

Özgen, Y. ve Gül, A. (2007). Sosyal ve eğitim bilimleri araştırmalarında evrenörneklem sorunu.Kazım Karabekir Eğitim Fakültesi Dergisi,0(15), 394-422.

Özyaprak, M. (2012). Üstün zekâhl ve yetenekli öğrencilere yönelik farkllaş̧tırlmış matematik öğretiminin erişi, tutum ve yaratıcliğg etkisi. Doktora Tezi. İstanbul Üniversitesi Sosyal Bilimler Enstitüsü, İstanbul.

Robinson, A., Shore, B. and Enersen, D. (2014). Üstün zekâllar eğitiminde en iyi uygulamalar. Ankara: Nobel.

Sayı, A. K. (2013). Farkllaştırlmış yabancı dil öğretiminin üstün zekâll öğrencilerde erişiye, eleştirel düşünmeye ve yaratıcilğa etkisi. Doktora Tezi. İstanbul Üniversitesi, Sosyal Bilimler Enstitüsü, İstanbul.

Schlichter, C. L. (1986). Talents unlimited: An inservice education model forteaching thinking skills. Gifted Child Quarterly, 30(3) 119-120.

Tharenou, P., Donohue, R. and Cooper, B. (2007). Management researchmethods. New York: Cambridge UniversityPress. 
Tuna, S. (2017). Sanatsal yetenekli çocuklar ve özellikleri. Mehmet Akif Ersoy Üniversitesi Ĕ̈itim Bilimleri Enstitüsü Dergisi, 1(1), 31.

Umar, Ç. N. (2014). Karma öğrenme yöntemi ile farkllaştırlmıs öğretim ortammmn üstün zekâh ve yetenekli öğrencilerin akademik başarlarnna, eleştirel düşünme becerilerine ve yaratıcllklarına etkisi. Doktora Tezi. İstanbul Üniversitesi, Eğitim Bilimleri Enstitüsü, İstanbul.

ÜIger, B. B. (2019). Üstün yetenekli öğrencilere yönelik farkhlaştırlmış sorgulama temelli fen bilgisi ders modüllerinin geliştirilmesi, uygulanmast ve etkililiğinin değerlendirilmesi. Doktora Tezi. Uludağ Üniversitesi, Eğitim Bilimleri Enstitüsü, Bursa.

\section{Kaynakça Bilgisi / Citation Information}

Kansu Çelik, F. ve Çaydere, O. (2021). geliştirilen farklılaştırma yaklaşımının sanat alanında üstün zekâlı ve özel yetenekli öğrencilerin yaratıcılıkları üzerindeki etkisi. OPUS-Uluslararası Toplum Araştırmaları Dergisi, 18(Eğitim Bilimleri Özel Sayısı), 4519-4538. DOI: 10.26466/opus.906214. 